\title{
A Novel Fault Identification Method Using Modified Morphological Denoising via Structuring Element Optimization for Transmission Systems of Shipborne Antennas
}

\author{
Zipeng Li ${ }^{1,2}$, Kunde Yang ${ }^{1,2}$, Jinglong Chen ${ }^{3}$ and Shunli Duan ${ }^{1,2, *}$ \\ 1 School of Marine Science and Technology, Northwestern Polytechnical University, Xi'an 710072, China; \\ class1lizp@nwpu.edu.cn (Z.L.); ykdzym@nwpu.edu.cn (K.Y.) \\ 2 Key Laboratory of Ocean Acoustics and Sensing, Ministry of Industry and Information Technology, \\ Northwestern Polytechnical University, Xi'an 710072, China \\ 3 State Key Laboratory for Manufacturing and Systems Engineering, Xi'an Jiaotong University, \\ Xi'an 710049, China; jlstrive2008@xitu.edu.cn \\ * Correspondence: duanshunli@nwpu.edu.cn; Tel.: +86-15829626511
}

check for

updates

Citation: Li, Z.; Yang, K.; Chen, J.;

Duan, S. A Novel Fault Identification Method Using Modified

Morphological Denoising via

Structuring Element Optimization for

Transmission Systems of Shipborne

Antennas. J. Mar. Sci. Eng. 2022, 10

190. https://doi.org/10.3390/

jmse10020190

Academic Editor: Md Jahir Rizvi

Received: 5 January 2022

Accepted: 26 January 2022

Published: 31 January 2022

Publisher's Note: MDPI stays neutral with regard to jurisdictional claims in published maps and institutional affiliations.

Copyright: (c) 2022 by the authors. Licensee MDPI, Basel, Switzerland. This article is an open access article distributed under the terms and conditions of the Creative Commons Attribution (CC BY) license (https:// creativecommons.org/licenses/by/ $4.0 /)$.

\begin{abstract}
Unlike common rotating machines, shipborne antennas always work under variable loads and suffer from extreme ocean conditions, which makes monitoring their condition and early fault identification necessary and challenging. However, extracting weak fault characteristics from vibration signals accurately and efficiently is difficult because of multi-modulation phenomenon and heavy noise. Therefore, an adaptive denoising method based on morphological filtering via structuring element optimization is proposed in this paper. The proposed method mainly includes two aspects: an adaptive spectrum segmentation algorithm via scale expression and a criterion based on the characteristic energy ratio for structuring element optimization. Experimental signals and a set of comparisons verify the effectiveness and robustness of the proposed method. The proposed method is also applied to identify an early antenna drivetrain fault in a real case, showing its superiority and effectiveness.
\end{abstract}

Keywords: vibration signal denoising; morphological filtering; parameter optimization; shipborne antenna drivetrains

\section{Introduction}

Shipborne antennas always suffer from severe ocean environments, such as salt spray, elevated temperatures and huge waves. Consequently, key components of the shipborne antenna drivetrain degenerate and are damaged inevitably after long-term operation, which may influence the pointing precision of the antenna and even cause marine perils $[1,2]$. Therefore, condition monitoring and fault alarms for shipborne antennas are necessary and have attracted great attention all over the world [3-5]. Many monitoring factors, including but not limited to vibration, acoustic signal, temperature and oil samples, are used to identify mechanical faults of key components [6,7].

Among all mechanical condition monitoring factors, vibration is regarded as the most effective factor and has been studied for decades [8-11]. Once a localized fault occurs on the surface of key components, such as bearings and gears, a series of periodic pulses will appear in the vibration monitoring signal because of the contact between the faults and their mating surfaces [11,12]. However, background noise generated by marine main engines may obscure weak fault characteristics. Therefore, the core of antenna drivetrain fault detection is noise reduction and fault feature extraction.

Currently, many advanced signal processing methods have been developed to deal with non-stationary dynamic vibration signals, such as Wavelet Transform (WT), Empirical Mode Decomposition (EMD), Spectrum Kurtosis (SK), Empirical Wavelet Transform (EWT), Variational Mode Decomposition (VMD) and Compressed Sensing (CS) [13-19]. Although 
these methods are widely used for mechanical fault diagnosis, it is still difficult for crews to understand their mathematical principles and modify their complicated algorithms. For example, the result of wavelet transform depends highly on the kind of wavelet basis function, and compound fault diagnosis even requires various basis functions to match different fault characteristics [20]. In yet another example, a reasonable result of VMD requires accurate mode numbers and bandwidth, which are hard to preset in practice because of heavy noise from main engines [21]. In brief, the aforementioned methods are inefficient in the fault detection of shipborne antenna drivetrains because of their limitations and low efficiency.

Fortunately, morphological analysis is introduced to the signal denoising area, and increasing attention has been paid in modifying morphological filters for rotating machine fault detection [22]. Morphological analysis, which is also called morphological filtering, is a time-domain signal processing algorithm and has the ability to extract the geometric structure of the periodic fault feature $[23,24]$. The research on morphological analysis focuses on two aspects: morphological operator design and structure element (SE) optimization.

In 2013, Raj and Murali proposed a new algorithm for SE selection based on kurtosis, thereby making the analysis free of empirical methods [25]. In 2016, Hu et al. chose a morphological gradient (MG) operator for denoising and adopted the harmonic waveform to instruct the structuring element, which is effective for bearing fault diagnosis [26]. In 2017, Li and Liang proposed a diagonal slice spectrum assisted optimal scale morphological filtering method (DSS-OSMF) and designed a corresponding morphological filter for mechanical fault extraction in the method [27]. In 2018, Lv optimized the structuring element by constructing several difference operators, integrating the best two operators as the final filter, and introduced a new operator to early mechanical fault detection [28]. In 2020, Li et al. applied a morphological method to time-frequency analysis of bearing monitoring signals and improved the ability of weak fault feature extraction [29]. In 2021, Chen et al. proposed an adaptive time-varying morphological filtering method, determining the structure element according to waveform characteristics of the vibration signal [30].

Over the same period, many scholars have attempted to exploit multi-scale morphological methods since the result of multi-scale analysis does not rely on the preset structural element. In 2011, Li et al. proposed a weighted multi-scale morphological gradient filter, which combines multi-scale denoising results according to a weight index [31]. In 2015, Jiang et al. determined scales of morphological filters adaptively, according to the timedomain waveform of vibration signals, and applied the method to hydraulic pump fault diagnosis [32]. In 2017, Zuo et al. selected frequency domain kurtosis as the standard for multi-scale morphological filter optimization and used the modified morphological method to extract the fault feature of railway wheels [33]. In 2018, Li used multi-scale morphological denoising to remove fault-unrelated components and then identified faults in planetary gearboxes by hierarchical permutation entropy [34]. In 2018, Liang et al. processed train axle bearing monitoring signals by using a multi-scale morphological method and then calculated more than 30 feature indicators for bearing fault diagnosis with different conditions [35]. However, these modified methods are all based on the local feature of the time-domain waveforms, such as local peak and local statistics. Once the raw signal is affected by heavy noise (such as main engine noise), fault features (expressed as local peaks or valleys) are submerged and ignored in the time domain.

In this study, we focus on SE optimization and propose a data-based SE optimization method to improve the performance of morphological filtering. An optimal morphological filter based on the morphological gradient (MG) operator is designed, and related algorithms are developed subsequently. The proposed method mainly includes three highlights: Firstly, a criterion for noise reduction performance is built based on the characteristic energy ratio. Secondly, the spectrum of the filtered signal is re-expressed in the scale domain for subsequent band partition. Thirdly, a new band partition and correction method is proposed in the paper. A simulation case and a test-rig case are illustrated to prove the effectiveness of the proposed method. It was also employed to detect a real drive chain 
fault on the research ship "Yuanwang" with much success. Comparative analysis between cases shows that the proposed method performs better than traditional ones, such as Spectral Kurtosis (SK) and Ensemble Empirical Mode Decomposition EEMD. The rest of this paper is organized as follows: A theoretical introduction of morphological filtering and the proposed modification are depicted in the Section 2, and two applications are shown to prove the effectiveness of the proposed method in Section 3. Finally, the result is discussed, and conclusions are drawn in Section 4.

\section{The Proposed Method}

The mathematical morphological method, which is initially applied in image processing, is also called binary morphology because it is applied to an image consisting of only two gray values. With the increasing demand of image processing, mathematical morphology is modified and introduced to all-gray-value image processing and named grayscale morphology [36,37]. Vibration signals used for condition monitoring and fault diagnosis are obviously all-gray-value signals. Therefore, grayscale morphology is only introduced in the following section.

In order to explain mathematical morphology and show its denoising performance clearly, a simulated signal consisting of periodical fault features is formulated. A vibration signal with periodical transient impulses can be expressed as shown in Equation (1):

$$
X(t)=A e^{-2 \pi c f t} \cos (2 \pi f t)
$$

where $t \geq 0 ; A$ denotes the amplitude of the signal; $c$ controls the damping characteristic of the system; $f$ represents the resonance frequency of the simulated signal; and it is also considered as the occurrence rate of the impulse. The simulated signal is structured as Equation (2) shows.

$$
X_{1}(t)=e^{0.06 \cdot 2 \pi \cdot 150 t} \sin \left(\sqrt{1-0.06^{2}} \cdot 2 \pi \cdot 150 t\right)
$$

The sample frequency of the simulated signal is set to $2000 \mathrm{~Hz}$, and the number of sampling points is 450 . The time-domain waveform of $X_{1}(t)$ is shown in Figure 1 . It is obvious that the length of the signal is $0.225 \mathrm{~s}$. Meanwhile, the amplitude here is dimensionless since it is only a measure of signal strength without any physical significance.

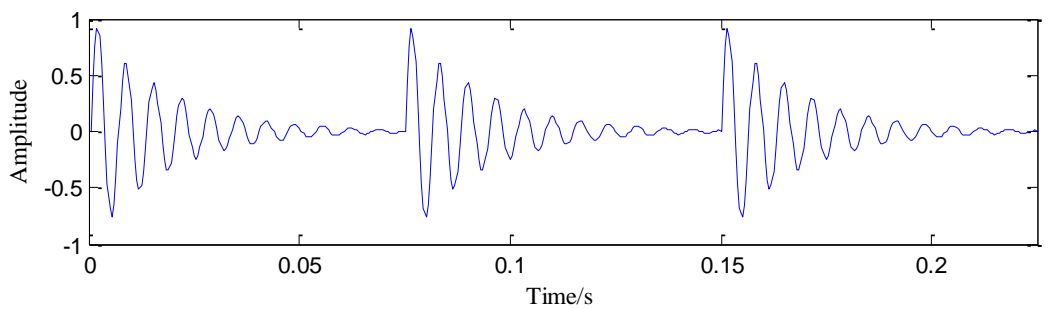

Figure 1. Waveforms of the simulated signal.

\subsection{A Brief Introduction of Morphological Signal Processing}

Similarly to the window function, the morphological filter modifies local characteristics of the signal through its interaction with various structuring elements. Supposing $x(i)$ is a discrete time sequence signal and $g(j)$ is a structuring element for which its length is far shorter than $x(i)$, we can define two basic operators of morphological filtering by Equations (3) and (4), respectively.

$$
\begin{aligned}
& \text { Dilation : }(x \oplus g)(i)=\max \{x(i-j)+g(j)\} \\
& \text { Erosion }:(x \ominus g)(i)=\max \{x(i+j)-g(j)\}
\end{aligned}
$$


Based on dilation operation and erosion operation, two other basic operators, opening and closing, can be also defined by Equations (5) and (6).

$$
\begin{gathered}
\text { Opening: }(x \circ g)(i)=(x \ominus g \oplus g)(i) \\
\text { Closing }:(x \cdot g)(i)=(x \oplus g \ominus g)(i)
\end{gathered}
$$

In order to show the different performance of four basic operators, we built a fundamental structuring element using length $\mathrm{L}=5$ and amplitude $\mathrm{H}=0$ and processed the simulated signal using four basic operators, respectively. The results are shown in Figures 2 and 3. It can be observed that the dilation operator can smooth positive impulses and reduce negative impulses, while the erosion operator is the opposite. The opening operator is capable of eliminating positive impulses, and the closing operator suffices to eliminate positive impulses of the time series. However, all basic operators change the morphological characteristics of periodical transient impulses, which may be caused by mechanical faults.
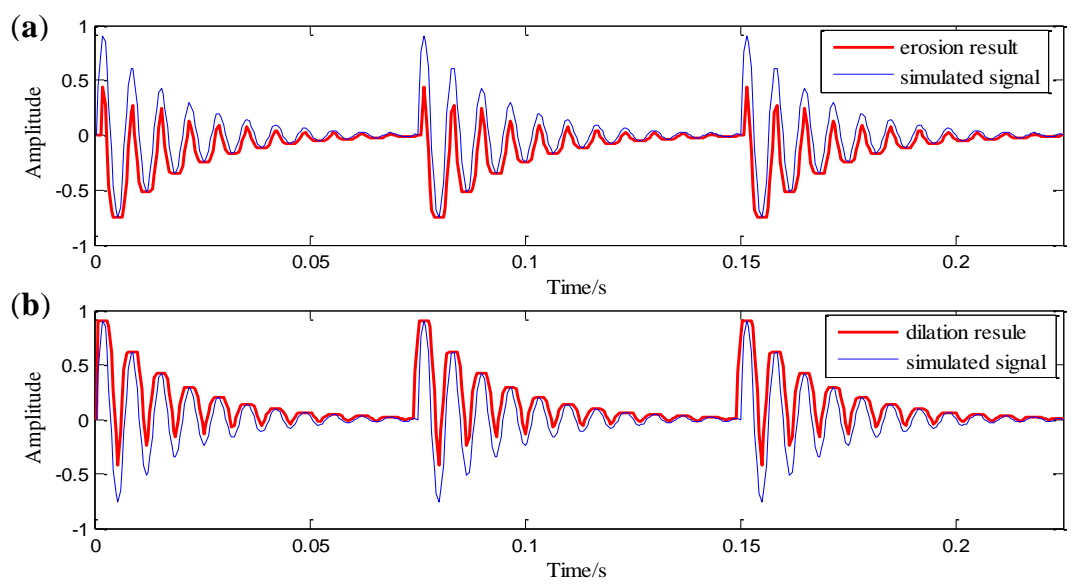

Figure 2. Filtering result of basic morphological operators: (a) erosion and (b) dilation.
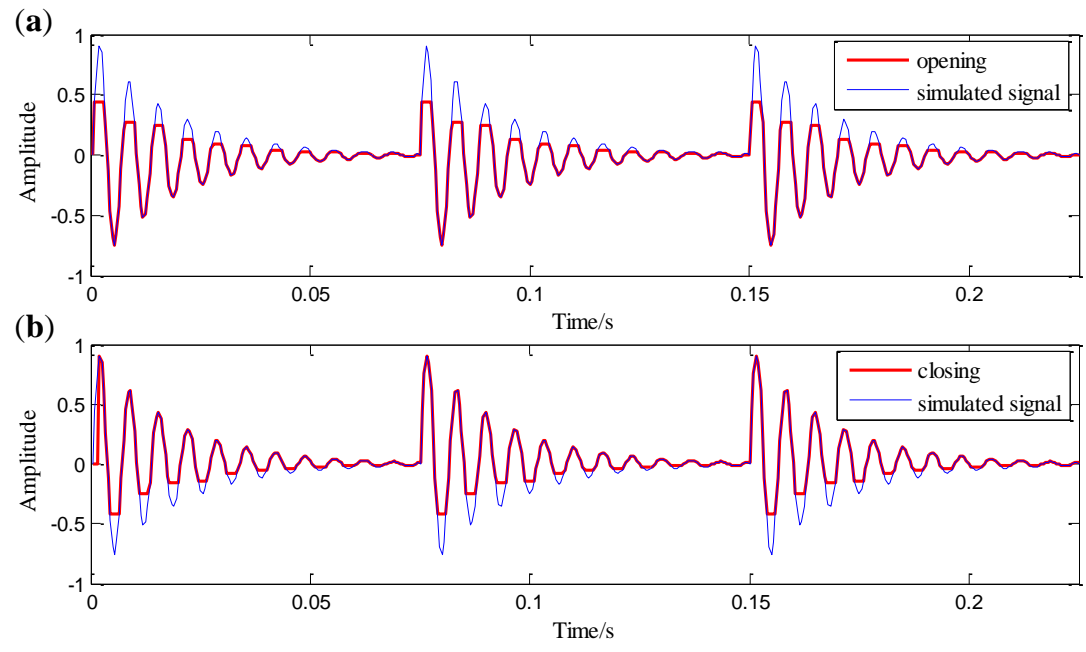

Figure 3. Filtering result of opening operator and closing operator: (a) opening and (b) closing.

Therefore, scholars construct various hybrid operators by combining four basic operators, such as a closing-opening operator, opening-closing operator, averaging operator and morphological gradient operator [30]. Since the aim of the proposed method is to seek and enhance the fault feature hidden in the raw vibration signal, we apply a morphological gradient operator as the optimal morphological operator, which is written as described in Equation (7).

$$
x_{\text {grad }}(i)=(x \oplus g)(i)-(x \ominus g)(i)
$$


The performance of a gradient operator is shown in Figure 4; it can be observed that the amplitude of periodical transient impulses is enhanced after filtering.

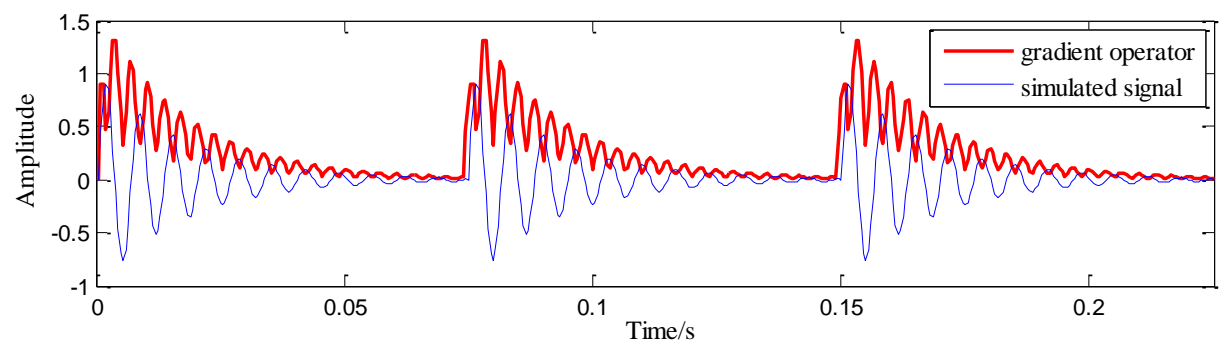

Figure 4. Filtering result of gradient operator.

\subsection{The Proposed Method for Fault Detection}

The main purpose of this paper is to improve the denoising ability of a morphological filter facing heavy noise in fault diagnosis for shipborne antenna drivetrains. Literature shows that the result of noise reduction highly depends on the length of a structuring element. Therefore, an adaptive structure optimization methodology is proposed in the paper, and the procedure is introduced as follows.

\subsubsection{The Procedure of the Proposed Method}

The flow diagram of the proposed method is shown in Figure 5. Firstly, once a raw signal is collected, the maximum of the element length is defined. Secondly, the raw signal is filtered by using a gradient operator of unequal length, and its spectrum is expressed in scale domain. Thirdly, the spectrum is divided into several sub-bands, and each sub-band is corrected according to its center frequency. Then, the characteristic energy ratio of each band is calculated, and the maximum among them is chosen as the filtering performance. Finally, the raw signal is denoised with the optimal length of the structuring element. It can be also observed that there are three key steps in each iteration, which include scale expression of filtered signals, adaptive frequency partition and criterion calculation, respectively. The details of the key steps are depicted in the following sections.

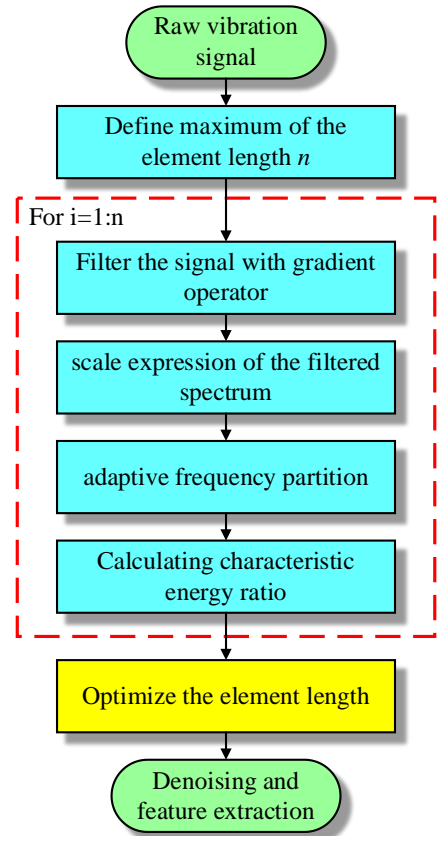

Figure 5. The flow diagram of the proposed method. 


\subsubsection{Scale Expression}

The spectrum of the raw signal needs to be divided into different sub-bands for criterion calculation and subsequent structuring element optimization. Considering interference and noise in the frequency domain, we represent and divide the spectrum in the scale domain. In order to obtain the scale expression of the spectrum of the filtered signal, a scaling kernel function should be selected first. Since the shape of the Gaussian kernel function is most similar to the fault feature in the low-frequency band, it is selected as the optimal kernel function and is defined by Equation (8):

$$
g(f, \sigma)=\frac{1}{\sqrt{2 \pi \sigma}} e^{-\frac{f^{2}}{2 \sigma^{2}}}
$$

where $\sigma$ denotes the scale factor. Generally, the suitable value of scale factor $\sigma$ lies between $2 f_{s}$ and $4 f_{s}[10]$, and the shape of the kernel function is shown in Figure 6 when we assigned $\sigma$ to $3 f_{s}$ ( $f_{s}$ is the rotating frequency).

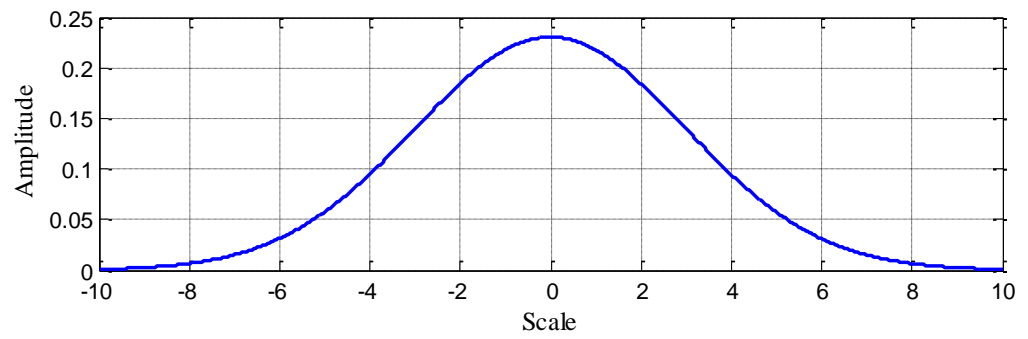

Figure 6. Shape of Gaussian kernel function.

Therefore, the scale expression of a one-dimensional vibration signal can be computed as follows:

$$
S(f, \sigma)=g(f, \sigma) * X(f)=\sum_{-\infty}^{+\infty} g(\tau, \sigma) X(f-\tau)
$$

where $X(f)$ is the frequency spectrum of the vibration signal. It can be observed that a scale expression is a convolution between the spectrum and the kernel function, and it can also be understood as a spectrum smoothing method. Due to the shape of Gaussian kernel function, a narrow neighborhood can ensure that the truncated discrete kernel function has a negligible approximation error, which is shown as follows.

$$
S(f, \sigma)=g(f, \sigma) * X(f)=\sum_{-2 f_{s}}^{+2 f_{s}} g(\tau, \sigma) X(f-\tau)
$$

In order to explain the proposed method more clearly, we extend the simulated signal and add white Gaussian noise with the signal-to-noise ratio per sample in $-2 \mathrm{~dB}$ to the signal. The noisy signal is shown in Figure 7. The signal is then filtered, and its spectrum is represented in a scale domain as Figure 8 shows. The scale feature of the spectrum is retained integrally for subsequent partition.

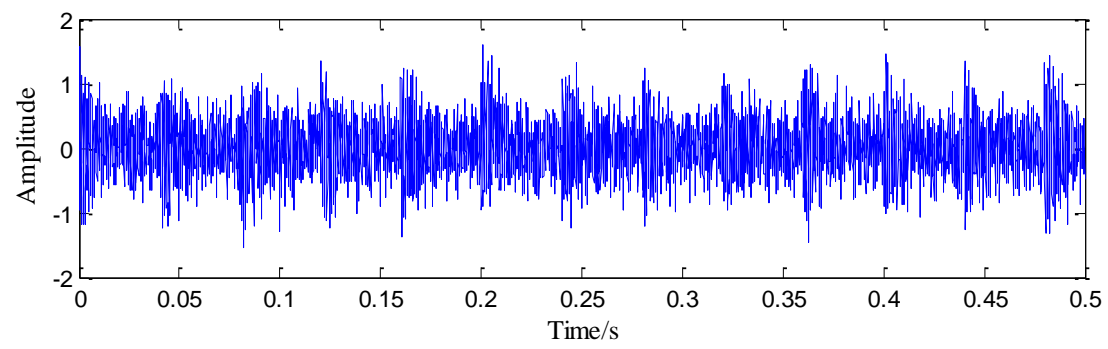

Figure 7. Waveform of the noisy simulated signal. 


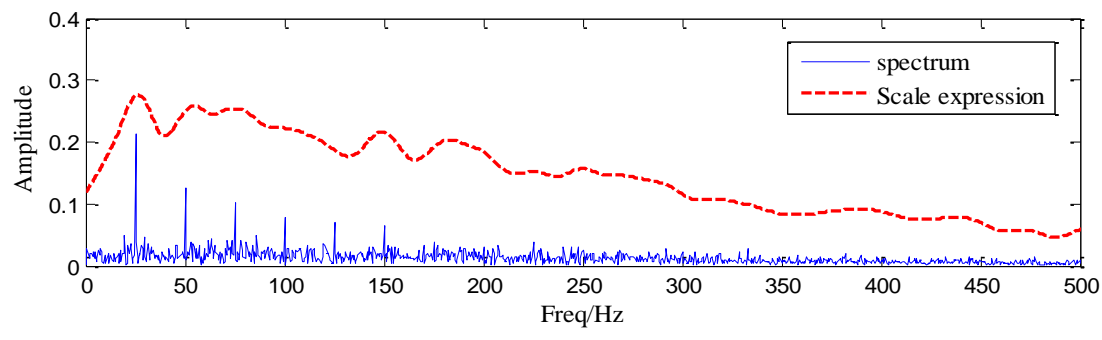

Figure 8. Spectrum and scale expression of the noisy simulated signal.

\subsubsection{Frequency Partition and Correction}

There are two aspects in this section, band partition and bandwidth correction, and they both pave the way for structuring element optimization. Firstly, by dividing the spectrum into several sub-bands, we find local minimum points of the scale expression of the filtered signal and then consider local minimum points as boundaries to separate adjacent sub-bands. The result of band partition is shown in Figure 9.

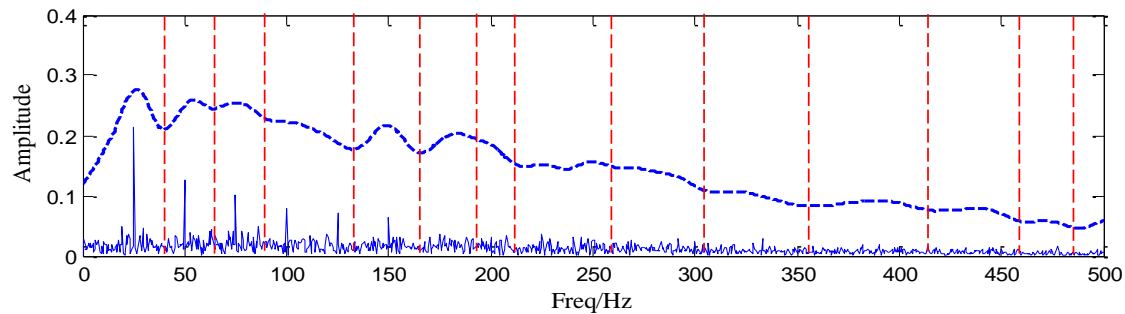

Figure 9. Result of frequency partition.

Secondly, the center frequency and bandwidth of each sub-band should be corrected. For each band, the center frequency will be replaced by the frequency at the maximum amplitude if the condition is not met, which is shown as follows:

$$
f_{c}{ }^{\prime}=f_{m} \text { if }\left|f_{m}-f_{c}\right| \geq \frac{\omega_{r}-\omega_{l}}{4}
$$

where $f_{c}$ is the center frequency, $f_{m}$ is the frequency at the maximum amplitude, $\omega_{r}$ is the right boundary of the sub-band and $\omega_{l}$ is the left boundary of the sub-band. Once the center frequency is replaced, bandwidth is also changed as follows.

$$
\left\{\begin{array}{l}
d=2\left|f_{c}^{\prime}-\omega_{r}\right| \text { if }\left|f_{c}{ }^{\prime}-\omega_{r}\right|<\left|f_{c}{ }^{\prime}-\omega_{l}\right| \\
d=2\left|f_{c}{ }^{\prime}-\omega_{l}\right| \text { if }\left|f_{c}{ }^{\prime}-\omega_{r}\right|>\left|f_{c}^{\prime}-\omega_{l}\right|
\end{array}\right.
$$

The correction result of the first band is shown in Figure 10, where the red dotted line denotes the corrected border.

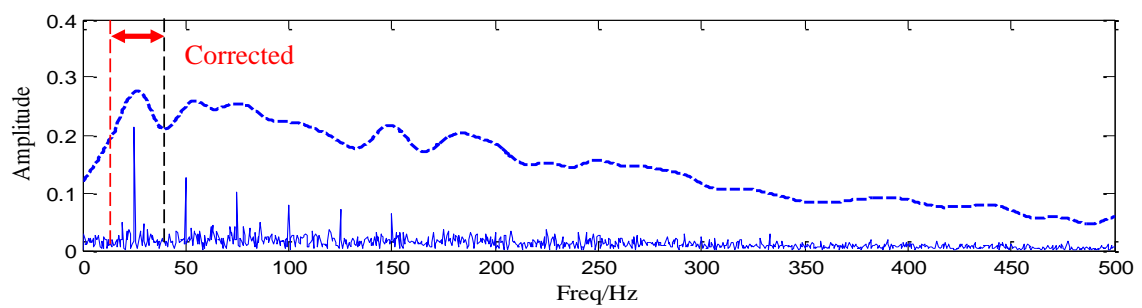

Figure 10. Correction result of the first band. 


\subsubsection{Filtering Performance Evaluation}

After frequency partition and correction, we calculate the characteristic energy ratio of each band and choose the maximum among all of them as the filtering performance, defining the characteristic energy ratio as Equation (13):

$$
K_{n}=\frac{\left[\max \left(F\left(e^{j \omega}\right)\right)\right]^{2}}{\int_{\omega_{n, l}}^{\omega_{n, l}}\left|F\left(e^{j \omega}\right)^{2}\right| d \omega}, \omega_{n, l} \geq j \geq \omega_{n, r}
$$

where $n$ denotes the number of sub-bands, $\omega_{n, l}$ and $\omega_{n, r}$ denote the left border and the right border of the $n$th sub-band, respectively. Therefore, $K_{n}$ reflects the intensity of the fault feature in the filtered signal. For the simulated fault signal, we chose the length of the structuring element from a collection $\{x=2,3, \ldots, 100\}$ and observed that the characteristic energy ratio reaches a peak when the length of the structuring element is set to 14 points, which is 0.3665 . The filtering result is shown in Figure 11 . Here, added white noise, which can be regarded as full-band interference in the spectrum, almost completely disappears.

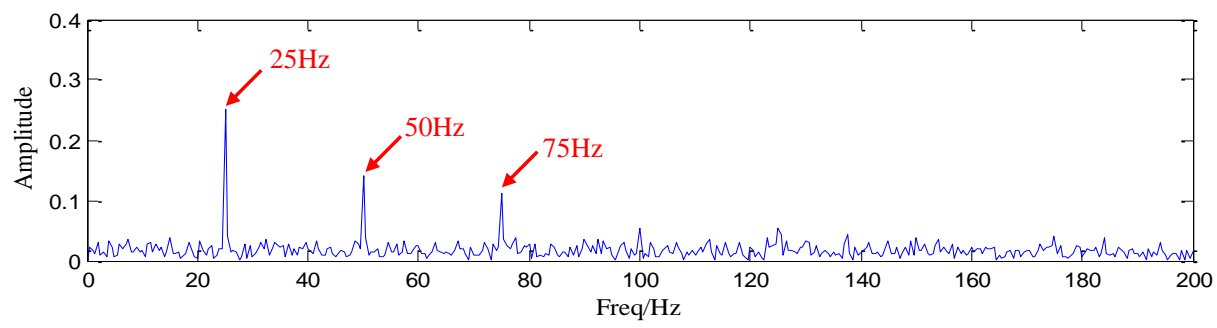

Figure 11. Filtering result of the simulated signal.

\section{Experimental Verification and Case Analysis}

\subsection{Experimental Setup}

3.1.1. Vibration Signal from Experimental Setup

In order to investigate the presence of fault features in the vibration signal using the proposed method, experiments were carried out on a motor-drive-brake-type test rig with a speed controller. A double-row tapered roller bearing with an artificial slight outer race defect is manufactured and installed into the test rig. An accelerometer is also installed on the bearing housing to collect vibration signals; thus, the unit of signals is in meters per square second. The test rig and the fault bearing are shown in Figure 12.
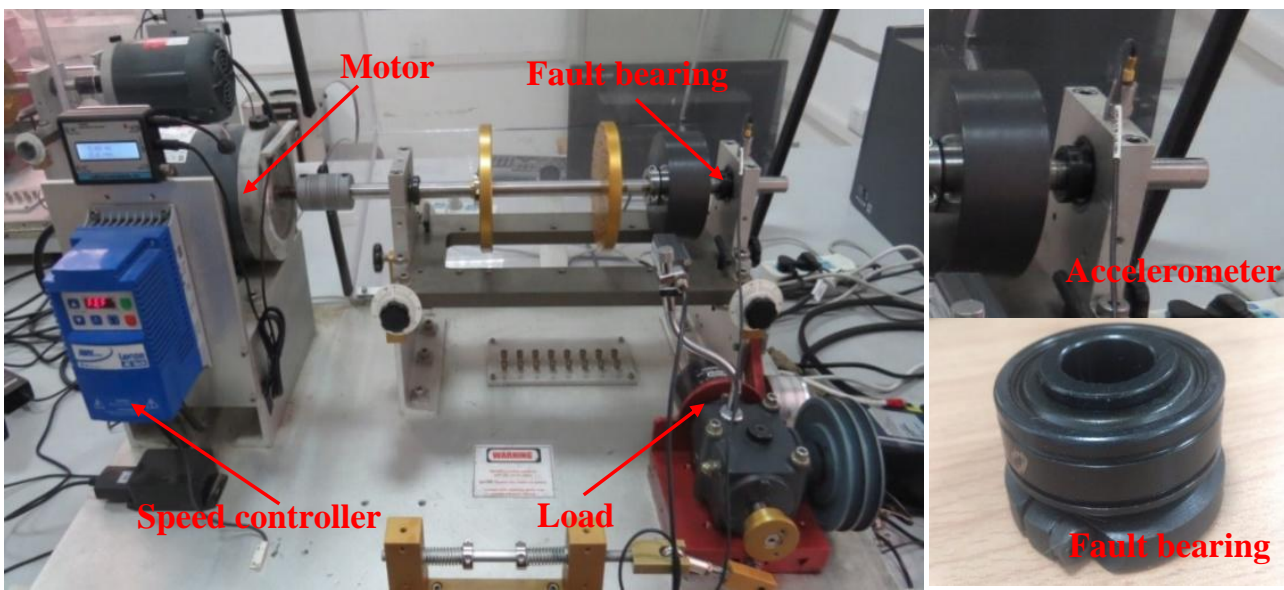

Figure 12. Setup and fault bearing.

The rotational speed was maintained at a constant value of $1200 \mathrm{rpm}$ by the speed controller, and vibration signals were gathered with a sampling rate of $12.8 \mathrm{kHz}$. Since 
fault characteristic frequency ratios of the bearing are listed in Table 1, the characteristic frequency of the outer race fault is calculated to be $71.44 \mathrm{~Hz}$. The time domain waveform, Fourier spectrum and envelope spectrum are shown in Figure 13 together.

Table 1. Characteristic frequency of fault bearing.

\begin{tabular}{cccc}
\hline Outer Race & Inner Race & Rolling Element & Holder \\
\hline 3.048 & 4.95 & 1.992 & 0.378 \\
\hline
\end{tabular}

(a)

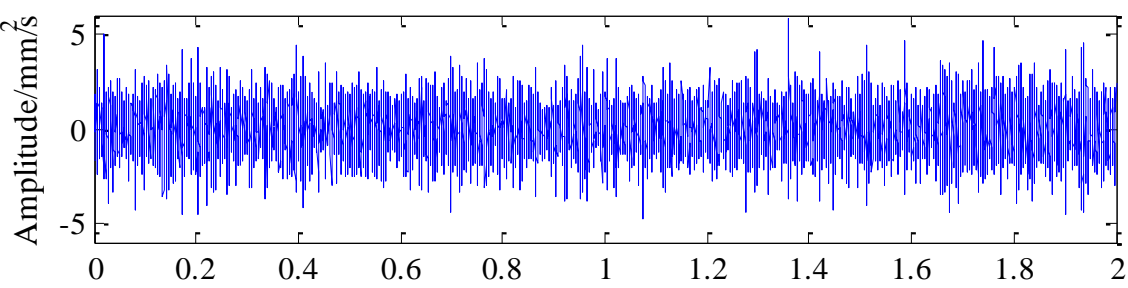

(b)

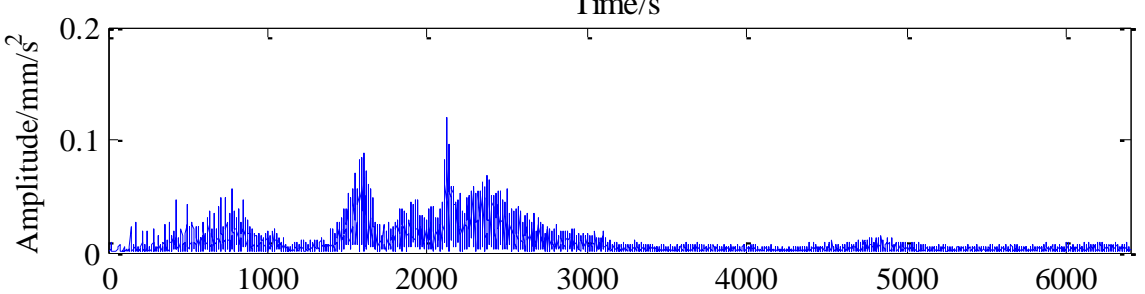

(c)

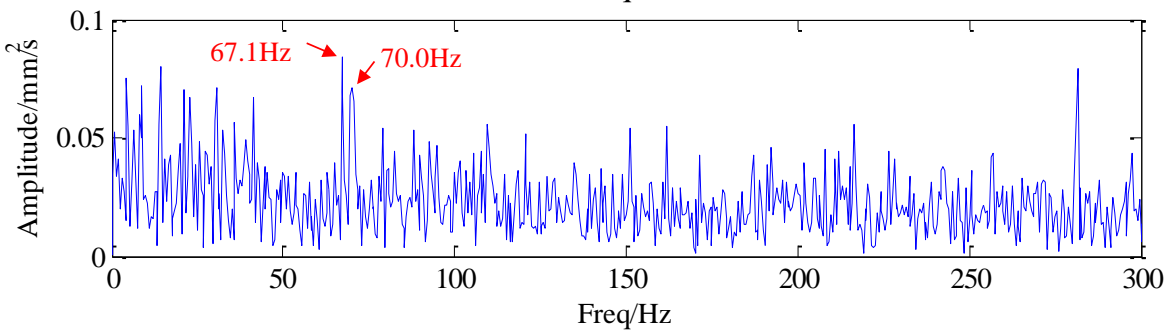

Figure 13. Fault bearing vibration signal: (a) waveform and (b) spectrum and (c) envelope spectrum.

\subsubsection{Fault Detection and Result Comparison}

In Figure 13c, the fault characteristic frequency $71.44 \mathrm{~Hz}$ cannot be identified clearly from the envelope spectrum because of heavy noise and interference. In order to inhibit noise and enhance fault features, the proposed method is applied for the bearing vibration signal. Since the raw signal contains 24,800 sampling points, the largest length of the structuring element is set to 248 points, and the search range is set to $\{2,3, \ldots, 248\}$ for the following optimization. The best filtering result is gained when the length of structuring element is set to 28 points, while the characteristic energy ratio reaches a peak of 0.448 . Figure 14 shows the waveform and frequency spectrum after adaptive filtering. Not only is the fault characteristic frequency identified clearly but a second harmonic pulse also appears in the spectrum. 
(a)

(b)
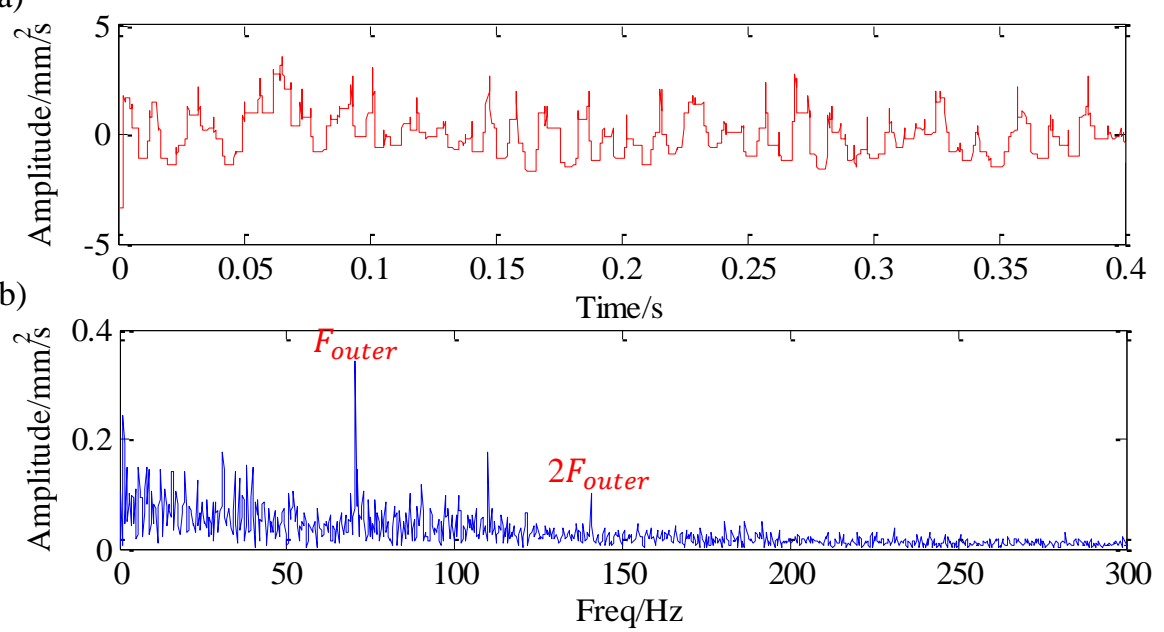

Figure 14. Filtered signal using the proposed method: (a) waveform and (b) spectrum.

For comparison purposes, wavelet denoising is employed to process the raw signal. Figure 15 shows the denoising result of a sym 8 wavelet based on a four-level soft thresholding strategy. According to the frequency spectrum shown in Figure 15a, the fault characteristic frequency can be scarcely confirmed. Although the characteristic frequency appears in the envelope spectrum shown in Figure 15b, the second harmonic pulse is submerged by other frequency components. Other irrelevant frequency components are also found in the envelope spectrum, such as $39.5 \mathrm{~Hz}$ and $110.0 \mathrm{~Hz}$, which influences the expression of the outer race fault characteristic.

(a)

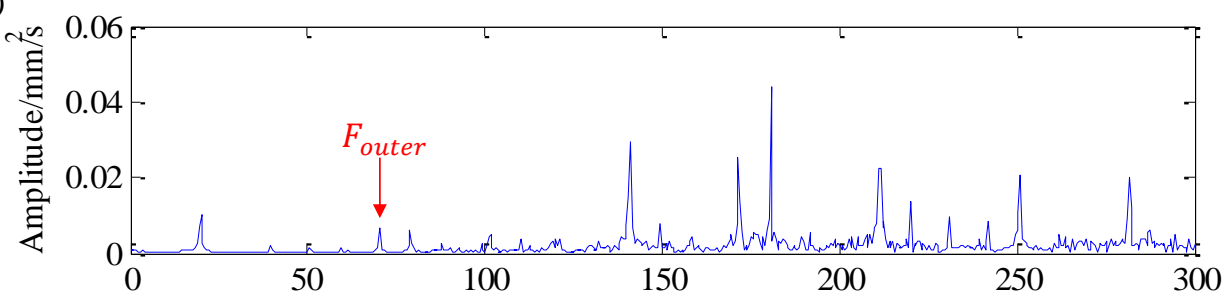

(b)

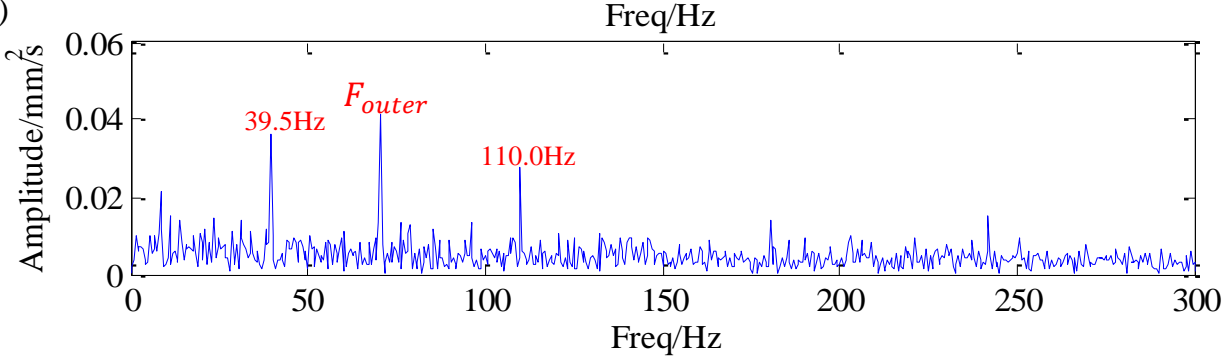

Figure 15. Filtered signal using waveform denoising: (a) frequency spectrum and (b) envelope spectrum.

\subsection{Fault Early Warming for Shipborne Antenna Drivetrains}

\subsubsection{Shipborne Antenna and Vibration Signal from Condition Monitoring System}

In this case, the proposed method is used for fault early warning of shipborne antenna drivetrains. Generally, a transmission system of shipborne antennas contains three driving chains, which control cross motion, pitch motion and rotation motion. The pitching axes with monitoring sensors are shown in Figures 16 and 17. Fault characteristic frequencies of bearings and gears are shown in Tables 2 and 3. 


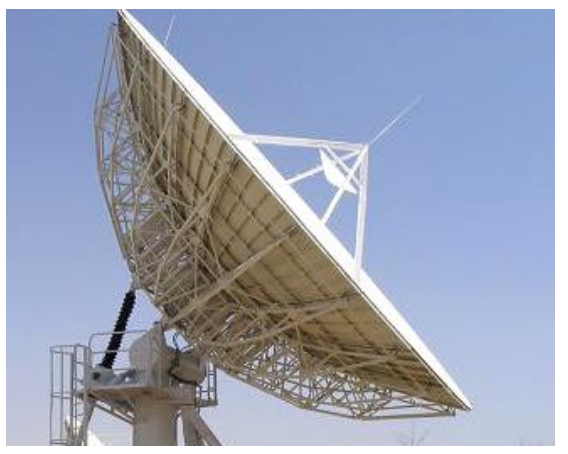

Figure 16. Shipborne antenna.

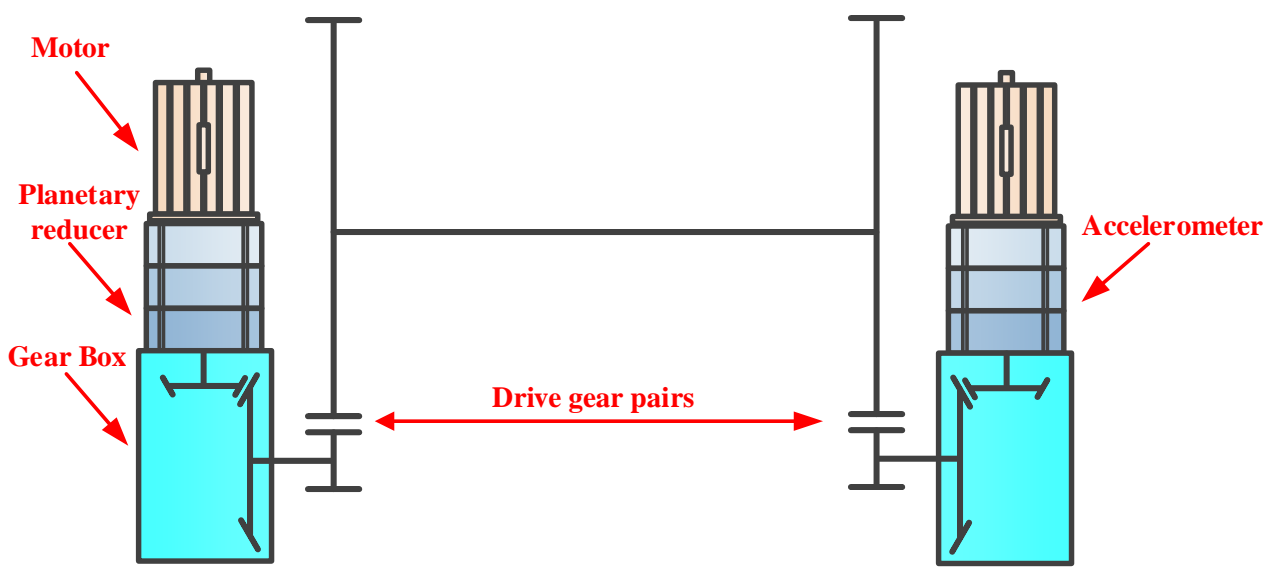

Figure 17. Structure chart of the pitching moving system and accelerometers.

Table 2. Characteristic frequency of 6402 deep-groove ball bearing.

\begin{tabular}{cccc}
\hline Outer Race & Inner Race & Rolling Element & Holder \\
\hline 3.57 & 5.43 & 0.40 & 2.32 \\
\hline
\end{tabular}

Table 3. Transmission parameters of the pitching moving system.

\begin{tabular}{|c|c|c|c|}
\hline Component & Level & Part & Teeth Number \\
\hline \multirow{6}{*}{ Planetary reducer } & \multirow{3}{*}{ First } & sun gear & 12 \\
\hline & & planet gear & 36 \\
\hline & & gear ring & 84 \\
\hline & \multirow{3}{*}{ Second } & sun gear & 28 \\
\hline & & planet gear & 28 \\
\hline & & gear ring & 84 \\
\hline \multirow{4}{*}{ Gearbox } & \multirow{2}{*}{ First } & input shaft gear & 19 \\
\hline & & output shaft gear & 38 \\
\hline & \multirow{2}{*}{ Second } & input shaft gear & 18 \\
\hline & & output shaft gear & 252 \\
\hline
\end{tabular}

In order to monitor the working conditions of shipborne antennas and predict mechanical faults, a condition monitoring and fault warning system was developed and used onboard, with the proposed denoising method embedded. The system can collect acceleration signals at the measuring points shown in Figure 17 with a $2048 \mathrm{~Hz}$ sampling frequency.

The research ship "Yuanwang" was on a mission in April 2019. A selected vibration signal of the right pitching axis on 4 April 2019 is shown in Figure 18, as well as its frequency spectrum and envelope spectrum. The motor rotation speed is $1350 \mathrm{rpm}$, and it can be observed that a spectral peak appears at $6.38 \mathrm{~Hz}$ (the characteristic frequency of the rolling 
element fault) in Figure 18. Therefore, we speculated about the rolling element fault and decided to use modified morphological filtering to enhance the fault feature.

(a)

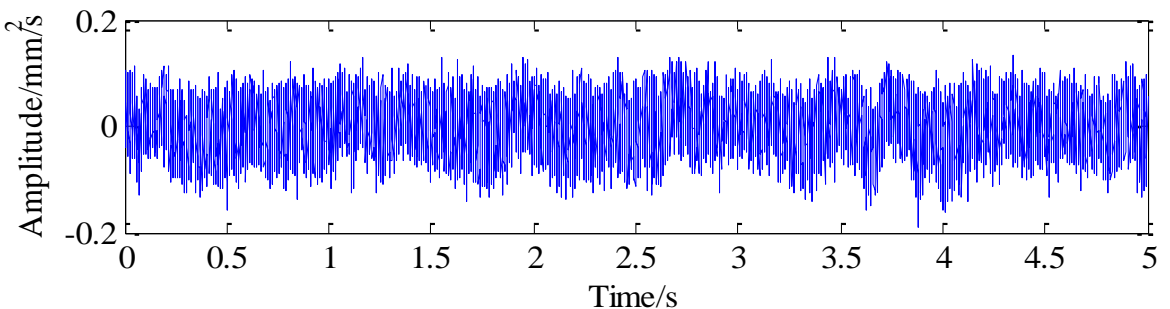

(b)

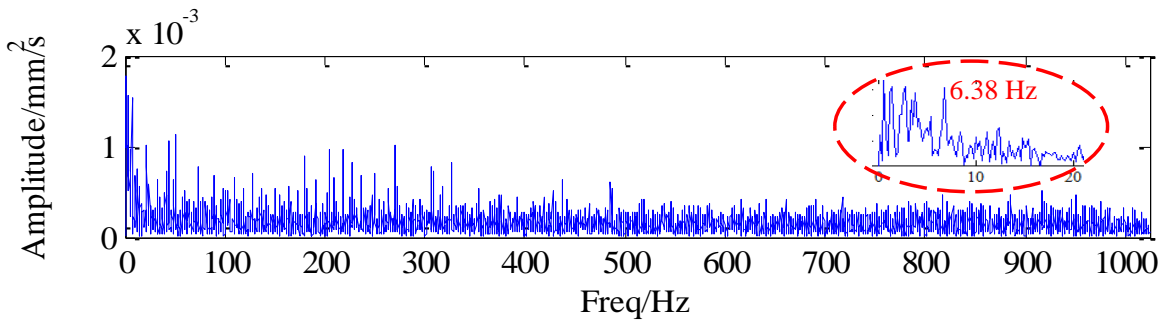

(c)

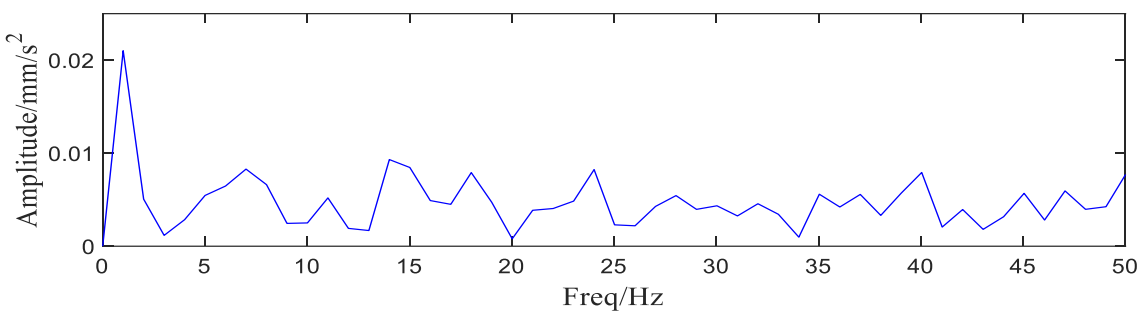

Figure 18. Vibration signal of the left pitching moving drivetrain: (a) waveform and (b) spectrum (c) envelope spectrum.

\subsubsection{Fault Identification Using the Proposed Method and Accident Analysis}

The proposed method is then employed to judge whether a rolling element fault had occurred. Since the length of the raw signal is 10,240 sampling points, the largest length of the structuring element is set to 100 points, and the search range is set to $\{2,3, \ldots, 100\}$ for the following optimization. The characteristic energy ratio reaches a peak when the length of the structuring element is set to 17 points. Dramatically, the characteristic frequency of the holder fault at $9 \mathrm{~Hz}$, rather than the characteristic frequency of the rolling element fault at $6.38 \mathrm{~Hz}$, is found in the spectrum shown in Figure 19.

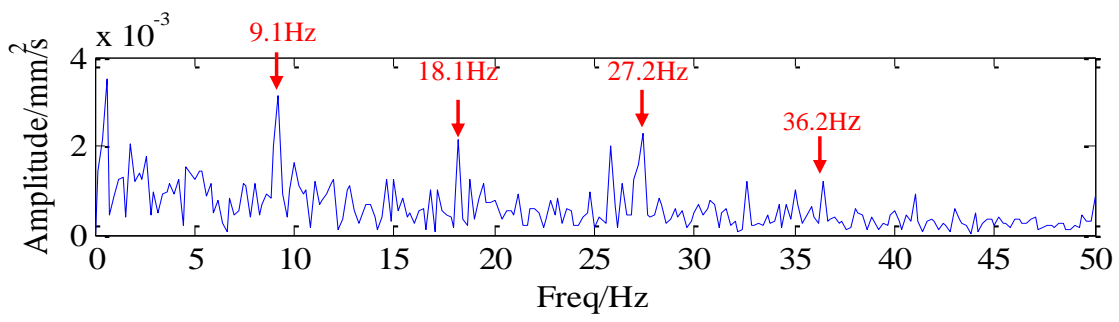

Figure 19. Spectrum of the filtered signal.

It is interesting that the proposed method draws a completely different result. The research ship "Yuanwang" reached port at the end of April 2019 and then began a new mission in September 2019. According to staff onboard, once the shipborne antenna was opened, a squealing noise appeared and the shipborne antenna subsequently malfunctioned. The planetary reducer was disassembled and checked, and several shed rolling elements were found in the reducer. Therefore, we conclude that the accident was caused by the bearing holder, which had torn gradually until it could not restrain the rolling elements. The faulty reducer is shown in Figure 20. 


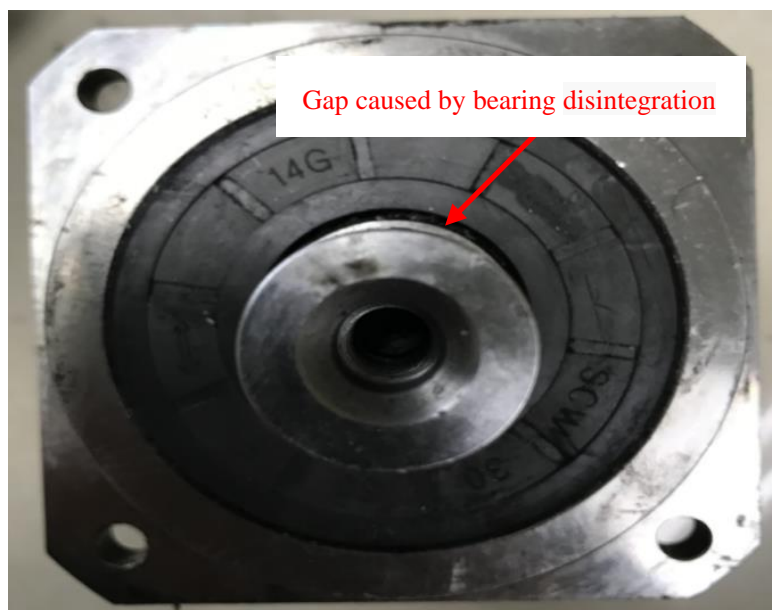

Figure 20. Faulty reducer.

\subsubsection{Comparison with Other Representative Method}

SK is applied to analyze the same signal for comparison. The optimal band (bandwidth $341.33 \mathrm{~Hz}$; center frequency $170.67 \mathrm{~Hz}$, level 1.5) associated with the largest kurtosis is shown in Figure 21a, whereas Figure 21b displays the envelope spectrum of the selected mode. However, the fault feature is not found in Figure 21b. Meanwhile, EEMD is also applied for comparison and decomposes the signal into 14 IMFs. Normally, the first six IMFs are considered as meaningful modes, and the others are regarded as useless low-frequency narrow-band sub-signals. For the sake of simplicity, envelope spectrums of the former six IMFs are shown in Figure 22. The fault feature with $9 \mathrm{~Hz}$ can be found in the second mode, the third mode and the fourth mode, but no harmonic pulses were clearly identified in either of the six envelope spectrums. Hence, neither SK nor EEMD can extract weak fault information from the vibration signal.

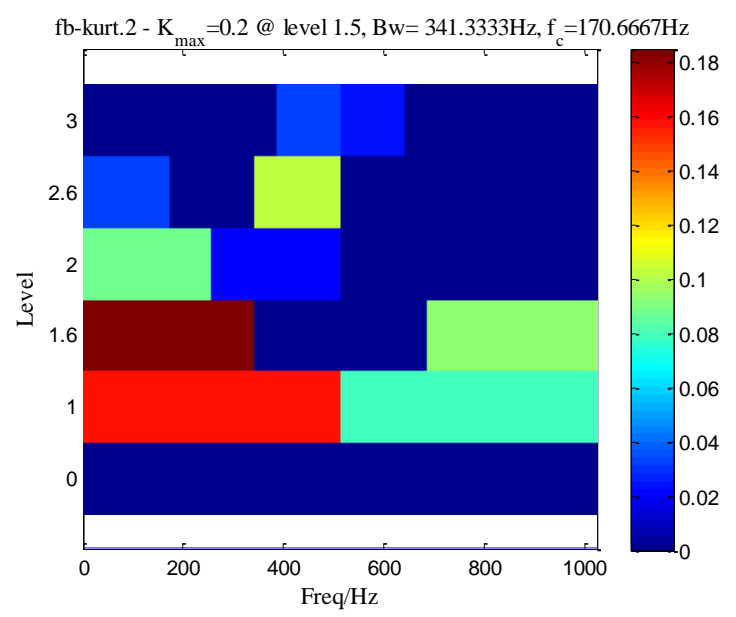

(a)

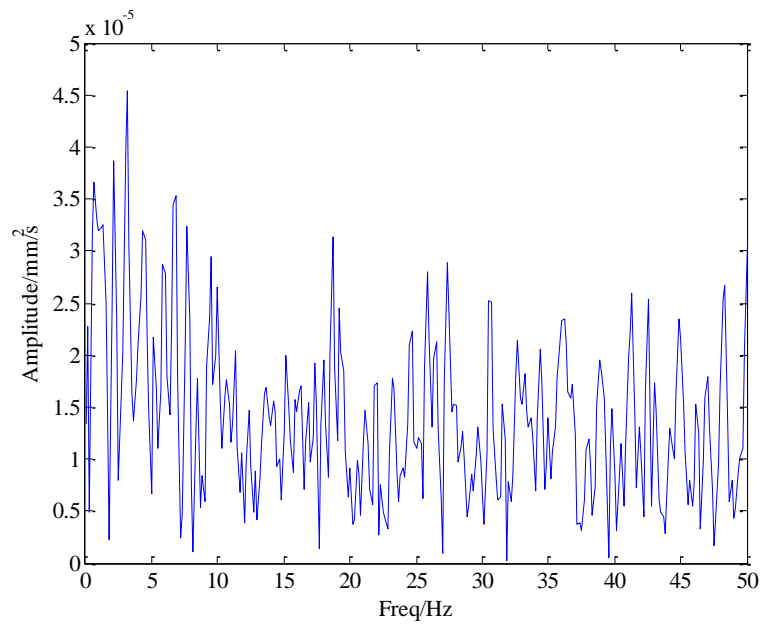

(b)

Figure 21. Result using spectral kurtosis: (a) band partition and (b) envelope spectrum. 


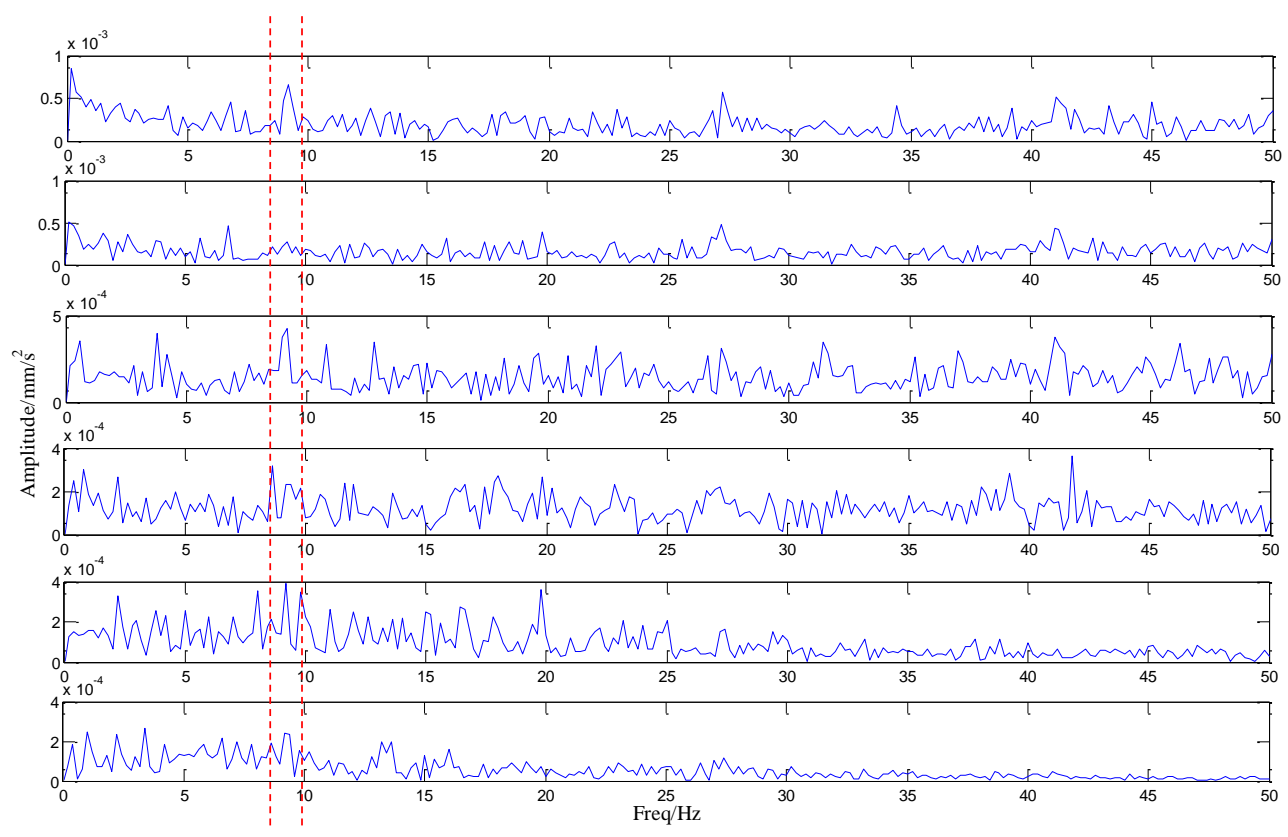

Figure 22. Result using EEMD.

\subsection{Discussion}

The fault detection outcomes using the four signal processing techniques are summarized in Table 4. In the table, Y states that the fault is completely detectable, and $\mathrm{N}$ means that the fault can be identified by the proposed method. Uncertain means that fault features are not clear. It can be understood from the table that the proposed method has the best capacity of denoising and fault diagnosis. Wavelet shows a dissatisfied result with lab data because it uses a fixed basic function to match fault features. Spectral kurtosis suffers from fixed binary band partition rules, and it extracts no fault features in both cases. Better than spectral kurtosis, EEMD can extract the characteristic frequency of the holder fault, but no harmonic pulses can be identified in the IMF's envelope spectrums.

Table 4. Fault identification outcomes using 4 methods.

\begin{tabular}{ccccc}
\hline Case & The Proposed Method & Wavelet & Spectral Kurtosis & EEMD \\
\hline 1 & $\mathrm{Y}$ & Uncertain & $/$ & $/$ \\
2 & $\mathrm{Y}$ & $/$ & $\mathrm{N}$ & Uncertain \\
\hline
\end{tabular}

\section{Conclusions and Discussion}

Condition monitoring and fault identification of shipborne antennas play a vital role in ship health management. In this paper, a modified denoising method based on morphological filtering via adaptive frequency partition is proposed to deal with vibration monitoring signals and identify mechanical faults.

The modified method has been used in two fault diagnosis cases and compared with other denoising methods, such as WT and SK. The second case shows the advantages of the proposed method over traditional methods. Some attractions of the paper can also be drawn after the above-mentioned work.

A novel denoising algorithm based on morphological filtering is proposed in this paper, which includes an adaptive spectrum segmentation algorithm via scale expression and a criterion based on the characteristic energy ratio for structuring element optimization.

Two cases show that the proposed method has a superior ability in denoising and fault extraction over traditional denoising methods. In particular, the second case proves that the proposed method can deal with a weak drivetrain fault effectively under heavy background noise. 
This paper provides a feasible and self-organizing tool for signal denoising and fault identification of the shipborne antenna drivetrains. The algorithm is also integrated into the shipboard diagnosis software.

Although the effectiveness of the proposed method has been verified in this paper, another interesting question is raised: Since an adaptive structuring element can not only improve the denoising performance but also deal with non-stationary signals, can we use a time-variant structuring element with an adaptive shape and length to match different details of time series for a better denoising results? Therefore, we will attempt to conduct further research on adaptive structuring element design in the future.

Author Contributions: Conceptualization, Z.L.; methodology, Z.L.; software, Z.L.; writing-original draft preparation, Z.L.; writing-review and editing, Z.L., J.C., S.D. and K.Y.; project administration, S.D. All authors have read and agreed to the published version of the manuscript.

Funding: This work was supported by the National Natural Science Foundation of China under Grant 42076198, in part by the National Natural Science Foundation of China under Grant 51875436. We would also like to thank our laboratory assistants for their great support in setting up the test rig.

Institutional Review Board Statement: Not applicable.

Informed Consent Statement: Not applicable.

Data Availability Statement: Data sharing not applicable.

Conflicts of Interest: The authors declare no conflict of interest.

\section{References}

1. Garbatov, Y.; Sisci, F.; Ventura, M. Risk-based framework for ship and structural design accounting for maintenance planning. Ocean. Eng. 2018, 166, 12-25. [CrossRef]

2. Li, Z.; Zi, Y.; Chen, J.; Pan, J.; Zhou, Z. Performance-guided maintenance policy and optimization for transmission system of shipborne antenna with multiple components. Ocean. Eng. 2020, 199, 106903. [CrossRef]

3. He, S.; Chen, J.; Zhou, Z.; Zi, Y.; Wang, Y.; Wang, X. Multifractal entropy based adaptive multiwavelet construction and its application for mechanical compound-fault diagnosis. Mech. Syst. Signal Process. 2016, 76, 742-758. [CrossRef]

4. Li, N.; Huang, W.; Guo, W.; Gao, G.; Zhu, Z. Multiple enhanced sparse decomposition for gearbox compound fault diagnosis. IEEE Trans. Instrum. Meas. 2019, 69, 770-781. [CrossRef]

5. Dibaj, A.; Ettefagh, M.M.; Hassannejad, R.; Ehghaghi, M.B. A hybrid fine-tuned VMD and CNN scheme for untrained compound fault diagnosis of rotating machinery with unequal-severity faults. Expert Syst. Appl. 2020, 167, 114094. [CrossRef]

6. Li, D.; Wang, Y.; Wang, J.; Wang, C.; Duan, Y. Recent advances in sensor fault diagnosis: A review. Sens. Actuators A Phys. 2020, 309, 111990. [CrossRef]

7. Saeed, U.; Jan, S.U.; Lee, Y.D.; Koo, I. Fault diagnosis based on extremely randomized trees in wireless sensor networks. Reliab. Eng. Syst. Saf. 2021, 205, 107284. [CrossRef]

8. Miao, Y.; Zhang, B.; Lin, J.; Zhao, M.; Liu, H.; Liu, Z.; Li, H. A review on the application of blind deconvolution in machinery fault diagnosis. Mech. Syst. Signal Process. 2022, 163, 108202. [CrossRef]

9. Lundgren, A.; Jung, D. Data-driven fault diagnosis analysis and open-set classification of time-series data. Control. Eng. Pract. 2022, 121, 105006. [CrossRef]

10. Zhao, D.; Gelman, L.; Chu, F.; Ball, A. Vibration health monitoring of rolling bearings under variable speed conditions by novel demodulation technique. Struct. Control. Health Monit. 2021, 28, e2672. [CrossRef]

11. Pan, J.; Chen, J.; Zi, Y.; Yuan, J.; Chen, B.; He, Z. Data-driven mono-component feature identification via modified nonlocal means and MEWT for mechanical drivetrain fault diagnosis. Mech. Syst. Signal Process. 2016, 80, 533-552. [CrossRef]

12. Kundu, P.; Darpe, A.K.; Kulkarni, M.S. Gear pitting severity level identification using binary segmentation methodology. Struct. Control. Health Monit. 2020, 27, e2478. [CrossRef]

13. Malhotra, A.; Minhas, A.S.; Singh, S.; Zuo, M.J.; Kumar, R.; Kankar, P.K. Bearing fault diagnosis based on flexible analytical wavelet transform and fuzzy entropy approach. Mater. Today Proc. 2021, 43, 629-635. [CrossRef]

14. Chen, J.; Li, Z.; Pan, J.; Chen, G.; Zi, Y.; Yuan, J.; Chen, B.; He, Z. Wavelet transform based on inner product in fault diagnosis of rotating machinery: A review. Mech. Syst. Signal Process. 2016, 70, 1-35. [CrossRef]

15. Sun, Y.; Li, S.; Wang, X. Bearing fault diagnosis based on EMD and improved Chebyshev distance in SDP image. Measurement 2021, 176, 109100. [CrossRef]

16. Wang, Y.; Xiang, J.; Markert, R.; Liang, M. Spectral kurtosis for fault detection, diagnosis and prognostics of rotating machines: A review with applications. Mech. Syst. Signal Process. 2016, 66, 679-698. [CrossRef] 
17. Li, Y.; Jiao, S.; Gao, X. A novel signal feature extraction technology based on empirical wavelet transform and reverse dispersion entropy. Def. Technol. 2020, 17, 1625-1635. [CrossRef]

18. Sharma, V.; Anand, P. Extraction of weak fault transients using variational mode decomposition for fault diagnosis of gearbox under varying speed. Eng. Fail. Anal. 2020, 107, 104204. [CrossRef]

19. Ganesan, V.; Das, T.; Rahnavard, N.; Kauffman, J.L. Vibration-based monitoring and diagnostics using compressive sensing. J. Sound Vib. 2017, 394, 612-630. [CrossRef]

20. Song, Y.; Zeng, S.; Ma, J.; Guo, J. A fault diagnosis method for roller bearing based on empirical wavelet transform decomposition with adaptive empirical mode segmentation. Measurement 2018, 117, 266-276. [CrossRef]

21. Miao, Y.; Zhao, M.; Yi, Y.; Lin, J. Application of sparsity-oriented VMD for gearbox fault diagnosis based on built-in encoder information. ISA Trans. 2020, 99, 496-504. [CrossRef] [PubMed]

22. Li, C.; Liang, M. Continuous-scale mathematical morphology-based optimal scale band demodulation of impulsive feature for bearing defect diagnosis. J. Sound Vib. 2012, 331, 5864-5879. [CrossRef]

23. Jean, S. Introduction to mathematical morphology. Comput. Vis. Graph. Image Processing 1986, 35, $283-305$.

24. Duan, R.; Liao, Y.; Yang, L.; Xue, J.; Tang, M. Minimum entropy morphological deconvolution and its application in bearing fault diagnosis. Measurement 2021, 182, 109649. [CrossRef]

25. Raj, A.S.; Murali, N. Early classification of bearing faults using morphological operators and fuzzy inference. IEEE Trans. Ind. Electron. 2012, 60, 567-574. [CrossRef]

26. Hu, Z.; Wang, C.; Zhu, J.; Liu, X.; Kong, F. Bearing fault diagnosis based on an improved morphological filter. Measurement 2016, 80, 163-178. [CrossRef]

27. Li, Y.; Liang, X.; Zuo, M.J. Diagonal slice spectrum assisted optimal scale morphological filter for rolling element bearing fault diagnosis. Mech. Syst. Signal Process. 2017, 85, 146-161. [CrossRef]

28. Lv, J.; Yu, J. Average combination difference morphological filters for fault feature extraction of bearing. Mech. Syst. Signal Process. 2018, 100, 827-845. [CrossRef]

29. Li, Y.; Liang, X.; Chen, Y.; Chen, Z.; Lin, J. Wheelset bearing fault detection using morphological signal and image analysis. Struct. Control. Health Monit. 2020, 27, e2619. [CrossRef]

30. Chen, B.; Song, D.; Zhang, W.; Cheng, Y.; Wang, Z. A performance enhanced time-varying morphological filtering method for bearing fault diagnosis. Measurement 2021, 176, 109163. [CrossRef]

31. Li, B.; Zhang, P.L.; Wang, Z.J.; Mi, S.S.; Liu, D.S. A weighted multi-scale morphological gradient filter for rolling element bearing fault detection. ISA Trans. 2011, 50, 599-608. [CrossRef] [PubMed]

32. Jiang, W.; Zheng, Z.; Zhu, Y.; Li, Y. Demodulation for hydraulic pump fault signals based on local mean decomposition and improved adaptive multiscale morphology analysis. Mech. Syst. Signal Process. 2015, 58, 179-205. [CrossRef]

33. Li, Y.; Zuo, M.J.; Lin, J.; Liu, J. Fault detection method for railway wheel flat using an adaptive multiscale morphological filter. Mech. Syst. Signal Process. 2017, 84, 642-658. [CrossRef]

34. Li, Y.; Li, G.; Yang, Y.; Liang, X.; Xu, M. A fault diagnosis scheme for planetary gearboxes using adaptive multi-scale morphology filter and modified hierarchical permutation entropy. Mech. Syst. Signal Process. 2018, 105, 319-337. [CrossRef]

35. Li, Y.; Liang, X.; Lin, J.; Chen, Y.; Liu, J. Train axle bearing fault detection using a feature selection scheme based multi-scale morphological filter. Mech. Syst. Signal Process. 2018, 101, 435-448. [CrossRef]

36. Serra, J.; Vincent, L. An overview of morphological filtering. Circuits Syst. Signal Processing 1992, 11, 47-108. [CrossRef]

37. Patargias, T.I.; Yiakopoulos, C.T.; Antoniadis, I.A. Performance assessment of a morphological index in fault prediction and trending of defective rolling element bearings. Nondestruct. Test. Eval. 2006, 21, 39-60. [CrossRef] 